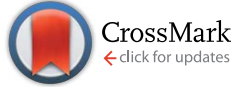

Cite this: J. Mater. Chem. A, 2015, 3 , 5962

Received 12th December 2014 Accepted 2nd February 2015

DOI: $10.1039 / c 4 t a 06848 c$

www.rsc.org/MaterialsA

\section{UV-assisted synthesis of indium nitride nano and microstructures $\dagger$}

\author{
Mahalieo Kao, ${ }^{\text {ab }}$ Rudolph M. Erasmus, ${ }^{\text {bd }}$ Nosipho Moloto, ${ }^{a}$ Neil J. Coville*ab \\ and Sabelo D. Mhlanga*bc
}

Indium nitride ( $\mathrm{InN}$ ) has been made the first time by a combined thermal/UV photo-assisted process. Indium oxide $\left(\mathrm{In}_{2} \mathrm{O}_{3}\right)$ was reacted with ammonia using two different procedures in which either the ammonia was photolysed or both $\ln _{2} \mathrm{O}_{3}$ and ammonia were photolysed. A wide range of $\ln N$ structures were made by these procedures that were determined by the reaction conditions (time, temperature). The reaction of $\mathrm{In}_{2} \mathrm{O}_{3}$ with photolysed $\mathrm{NH}_{3}$ gave $\mathrm{InN}$ rod-like structures that were made of stacked cones $\left(6 \mathrm{~h} / 750{ }^{\circ} \mathrm{C}\right)$ or discs $\left(6 \mathrm{~h} / 800{ }^{\circ} \mathrm{C}\right)$ and that contained some $\ln _{2} \mathrm{O}_{3}$ residue. In contrast, photolysis of both $\ln _{2} \mathrm{O}_{3}$ and $\mathrm{NH}_{3}$ gave InN nanowires and pure InN nanotubes filled with In metal (>90\%). The transformation of the 3D $\ln _{2} \mathrm{O}_{3}$ particles to the tubular 1D $\operatorname{lnN}$ was monitored as a function of time $(1-4 \mathrm{~h})$ and temperature $\left(700-800^{\circ} \mathrm{C}\right)$; the product formed was very sensitive to temperature. The band gap of the $\ln$ filled $\ln N$ nanotubes was found to be $1.89 \mathrm{eV}$.

\section{Introduction}

InN is an understudied material because it is difficult to produce due to its low decomposition temperature and its high equilibrium pressure with $\mathrm{N}_{2} \cdot{ }^{1}$ This has led to many controversies about the properties of this material. The inconsistencies and lack of reproducibility observed in the reported syntheses for this material escalates the problem.

InN has been grown with morphologies that range from one dimension (1D) to three dimensions (3D). ${ }^{2,3} 1 \mathrm{D}$ nanostructures are of particular importance in nanoscience and nanotechnology since they can be used to control space-confined transport phenomena, ${ }^{4,5}$ exhibit a discrete density of states and at the same time maintain a continuous transport path. ${ }^{6}$ They are of great importance in the understanding of the fundamental properties of low dimensional systems, and for use in potential nanodevice applications. ${ }^{7}$

Chemical vapour deposition (CVD) has proven to be a feasible method to prepare $1 \mathrm{D}$ InN nanomaterials. ${ }^{8-11}$

\footnotetext{
${ }^{a}$ Molecular Sciences Institute, School of Chemistry, University of the Witwatersrand, Johannesburg 2050, South Africa. E-mail: Neil.coville@wits.ac.za

${ }^{b} D S T-N R F$ Centre of Excellence in Strong Materials, University of the Witwatersrand, Johannesburg 2050, South Africa

'Nanotechnology and Water Sustainability Research Unit, College of Science, Engineering and Technology, University of South Africa, Florida Science Campus, Johannesburg, South Africa.E-mail: mhlansd@unisa.ac.za

${ }^{d}$ Raman and Luminescence Laboratory, School of Physics, University of the Witwatersrand, Johannesburg 2050, South Africa

$\dagger$ Electronic supplementary information (ESI) available: XRD patterns of InN materials with oxide impurities synthesised from a reaction of $\operatorname{In}_{2} \mathrm{O}_{3}$ with photolysed $\mathrm{NH}_{3}$ at different temperatures for a period of $6 \mathrm{~h}$. See DOI: $10.1039 / \mathrm{c} 4 \mathrm{ta} 06848 \mathrm{c}$
}

Temperature has been identified as a driving force that determines the different types of morphologies of the $1 \mathrm{D}$ InN nanostructures synthesised by CVD. ${ }^{11-13}$ The many studies reported on the synthesis of $1 \mathrm{D}$ InN using CVD have related to InN nanowires while much less work has been done on the synthesis of InN nanotubes. ${ }^{7,10-12,14}$

$\mathrm{In}_{2} \mathrm{O}_{3}$ is very attractive as an indium source in CVD studies due to the ease with which it can be handled. Body centred cubic $\mathrm{In}_{2} \mathrm{O}_{3}$ with space group Ia3 has a direct band gap and dominant ionic bonding. ${ }^{15}$ The magnitudes of the absorption and reflection coefficients for $\operatorname{In}_{2} \mathrm{O}_{3}$ are low, in the energy range $0-5 \mathrm{eV}$, indicating transparency in the material. ${ }^{15}$ It has a band gap of $3.6 \mathrm{eV}^{16}$

Several CVD studies have reported on the use of $\operatorname{In}_{2} \mathrm{O}_{3}$ for the preparation of InN. Zhang et al. reported the synthesis of InN nanowires through nitridation of a mixture of In metal and $\mathrm{In}_{2} \mathrm{O}_{3}$ (mole ratio $4: 1$ ) at $700{ }^{\circ} \mathrm{C}$ for a reaction time of $4 \mathrm{~h}$ in $\mathrm{NH}_{3}{ }^{8}{ }^{8}$ However the XRD pattern of the InN showed the existence of an oxide impurity. On the other hand Tang et al. have reported the preparation of single crystal InN nanowires by nitriding a mixture of In metal and $\operatorname{In}_{2} \mathrm{O}_{3}$ (mole ratio $\sim 5: 1$ ) at $525{ }^{\circ} \mathrm{C}$ for a period of 30 min under $\mathrm{NH}_{3}$, based on a SAED pattern of a hexagonal crystal system and Raman spectroscopy. ${ }^{9}$ At the other extreme, carbonitridation of $\operatorname{In}_{2} \mathrm{O}_{3}$ via CVD for $1.5 \mathrm{~h}$ was reported to give InN nanowires at $1150-1180{ }^{\circ} \mathrm{C}$ and InN nanotubes at $1190-1220{ }^{\circ} \mathrm{C} .{ }^{14}$ Gao et al. reported complete nitridation of nanosized $\operatorname{In}_{2} \mathrm{O}_{3}$ and $\mathrm{In}(\mathrm{OH})_{3}$ powders within $8 \mathrm{~h}$ at $600{ }^{\circ} \mathrm{C}$ under $\mathrm{NH}_{3} \cdot{ }^{17}$ In contrast, Luo et al. have reported several studies on the synthesis of InN and reported complete conversion of $\operatorname{In}_{2} \mathrm{O}_{3}$ powder to $\mathrm{InN}$ nanowires at $700{ }^{\circ} \mathrm{C}$ for a reaction period of $8 \mathrm{~h}$ in $\mathrm{NH}_{3}$ whereas for a shorter time period 
(4 h) oxide impurities were noted in their study. ${ }^{18}$ In a related study, done by a different group, a change in dimensionality on nitridation of $\operatorname{In}_{2} \mathrm{O}_{3}\left(650-700{ }^{\circ} \mathrm{C}\right.$ for $\left.4 \mathrm{~h}\right)$, was reported. ${ }^{11}$ Dimensional and structural evolution from 1D InN nanowires to $2 \mathrm{D}$ InN plates was achieved through temperature increments of $25^{\circ} \mathrm{C}^{11}$ Luo et al. also reported on the impact of reaction time on the morphologies of structures resulting from nitridation of $\mathrm{In}_{2} \mathrm{O}_{3}$ at $680{ }^{\circ} \mathrm{C}$ in the presence of a gold catalyst. In this study, both InN nanowires (14 h) and InN nanobelts (38 h) were produced..$^{19}$ In yet another study at, $680{ }^{\circ} \mathrm{C}$, Luo et al. made pure InN nanobelts $(22 \mathrm{~h})$; microtubes coexisting with nanobelts after $26 \mathrm{~h}$, but after $30 \mathrm{~h}$ microtubes dominated. ${ }^{10}$ It has also been reported that a dramatic change in InN morphology with temperature indicated predominant involvement of $\operatorname{In}_{2} \mathrm{O}$ gas, formed from the decomposition of $\operatorname{In}_{2} \mathrm{O}_{3}$, in the growth of $\mathrm{InN}$ structures. $^{12}$

It can be seen from the studies mentioned that the standard reaction parameters for the synthesis of $\mathrm{InN}$ tubes from $\operatorname{In}_{2} \mathrm{O}_{3}$ have not yet been confirmed and agreed upon. The reported reaction parameters show wide ranges involving a single parameter such as the type of nitrogen source $\left(\mathrm{N}_{2}, \mathrm{NH}_{3}\right)$, the

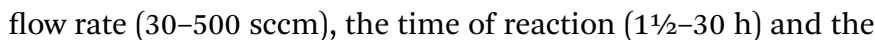
temperature (680-1220 $\left.{ }^{\circ} \mathrm{C}\right) .^{7,10-12,14}$ More than two thirds of the reported InN tubes are in the micrometer scale and the longest InN tubes reported are several microns in length. ${ }^{7}$

This study reports on the first UV photochemical synthesis of a range of InN structures as well as partially filled indium nitride nanotubes by photo-assisted nitridation of $\operatorname{In}_{2} \mathrm{O}_{3}$ in $\mathrm{NH}_{3}$. Photoassisted reactions are typically done with lasers due to their high peak intensities. ${ }^{20}$ However, UV-photochemical vapour deposition (UV-CVD) has been successfully used in the past to deposit numerous metals, insulators, and semiconducting films. ${ }^{21-23}$ In photochemical reactions, absorption of light by a reactant molecule enables an inaccessible reaction path to occur by bringing the reactants to the necessary activation energy and also by changing the symmetry of the reactant's electronic configuration. ${ }^{24}$ Medium pressure mercury UV lamps are important radiation sources for photochemical applications. When medium pressure mercury lamps are used more energy levels are excited resulting in more spectral lines as well as a continuum due to recombination radiation. ${ }^{25}$ The major UV spectral lines emitted by these lamps are at $254 \mathrm{~nm}(4.8 \mathrm{eV})$ and $185 \mathrm{~nm}$ $(6.7 \mathrm{eV})$. The majority of the UV-photochemical studies reported to date has focused on the deposition of two dimensional (2D) structures (i.e. thin films). ${ }^{26}$ Most films are normally produced using plasma deposition techniques in glow discharge.

UV-photochemical deposition of 1D group III-nitride nanostructures, with $\mathrm{NH}_{3}$, is not well established. Boron nitride nanotubes were synthesized by using excimer laser ablation at $1200{ }^{\circ} \mathrm{C}$ in different carrier gases. ${ }^{27} \mathrm{~A}$ few UV-synthesis studies have been reported on $1 \mathrm{D}$ gallium nitride (GaN) nanostructures. Shi et al. reported on GaN nanowires made from gallium oxide, using an excimer pulsed laser. ${ }^{28}$ Lieber and Duan also synthesised GaN nanowires by laser ablation of a metal containing target. ${ }^{29}$ There are however, to our knowledge, no studies reported on UV-CVD synthesis of one dimensional (1D) IIInitrides in general, and specifically on indium nitride (InN).

\section{Results and discussion}

\subsection{InN synthesis by photolysis of only $\mathrm{NH}_{3}$}

The effect of photo-activating only the ammonia in the nitridation of $\operatorname{In}_{2} \mathrm{O}_{3}$, was investigated by placing a boat containing $\mathrm{In}_{2} \mathrm{O}_{3}$ downstream out of the UV-light (i.e. the sample was protected from the UV light) (Fig. 1, position 1). In the absence of photolysis and using this configuration, $\left(T>700{ }^{\circ} \mathrm{C}\right)$ no InN was formed. Also, photolysis performed below $700{ }^{\circ} \mathrm{C}$, yielded no InN. This is to be contrasted with reports on the production of InN at much lower temperatures using plasma assisted CVD. ${ }^{30}$

Reactions involving the photolysis of $\mathrm{NH}_{3}$ in position 1 (Fig. 1) were also performed for $6 \mathrm{~h}$ at 700,750 and $800{ }^{\circ} \mathrm{C}$ and soft black powders or dark brown fluffy materials were produced and collected from the quartz boat. In reactions performed for shorter times, the product was dominated by $\operatorname{In}_{2} \mathrm{O}_{3}$ (see Table $\mathrm{S} 1 \dagger$ ).

The XRD patterns of the as-synthesised materials made at 700-800 ${ }^{\circ} \mathrm{C}$ (Fig. $\mathrm{S} 1 \dagger$ ) revealed that after $6 \mathrm{~h}$ wurtzite InN was formed in all reactions but the product contained varying amounts of $\operatorname{In}_{2} \mathrm{O}_{3}$. XRD analysis showed that $\operatorname{In}_{2} \mathrm{O}_{3}$ in the product did not decrease substantially with increasing temperature as one might expect. Microscopy analysis also revealed that the indium oxide signals found in the InN XRD pattern are due to large residual $\operatorname{In}_{2} \mathrm{O}_{3}$ particles which did not completely react; the residual $\operatorname{In}_{2} \mathrm{O}_{3}$ was not due to a residual oxide coating of the InN. For materials made at $800^{\circ} \mathrm{C}$ after $6 \mathrm{~h}$ reaction, spherical droplets of metallic indium were also observed at the bottom of the quartz boat. The images shown in Fig. 2 correspond to InN structures and indicate the variability in InN morphologies formed by variation in temperature.

TEM and SEM images of the precursor $\operatorname{In}_{2} \mathrm{O}_{3}$ prior to reaction showed solid agglomerated well defined 3D facetted particles with varying dimensions (Fig. 2a and b). Higher magnification SEM images reveal that all the particle tips sticking out from the agglomerate have rhombohedral-like faces varying in size that depend on both the size of the parent particle and the extent it is embedded into the agglomerate (Fig. 2b insert). TEM and SEM analyses of the collected materials after $6 \mathrm{~h}$ at $700{ }^{\circ} \mathrm{C}$ showed that the product consisted of an

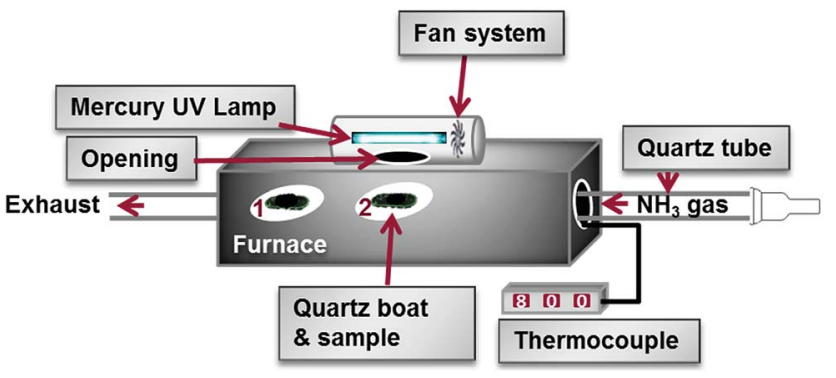

Fig. 1 A horizontal CVD furnace with a mercury UV lamp housing equipped with a cooling fan system. Position 1 is the position where $\mathrm{NH}_{3}$ was irradiated but the quartz boat and its contents were not irradiated by UV-light. Position 2 marks the position where the $\mathrm{NH}_{3}$, the quartz boat and its contents are illuminated by the UV-light. 


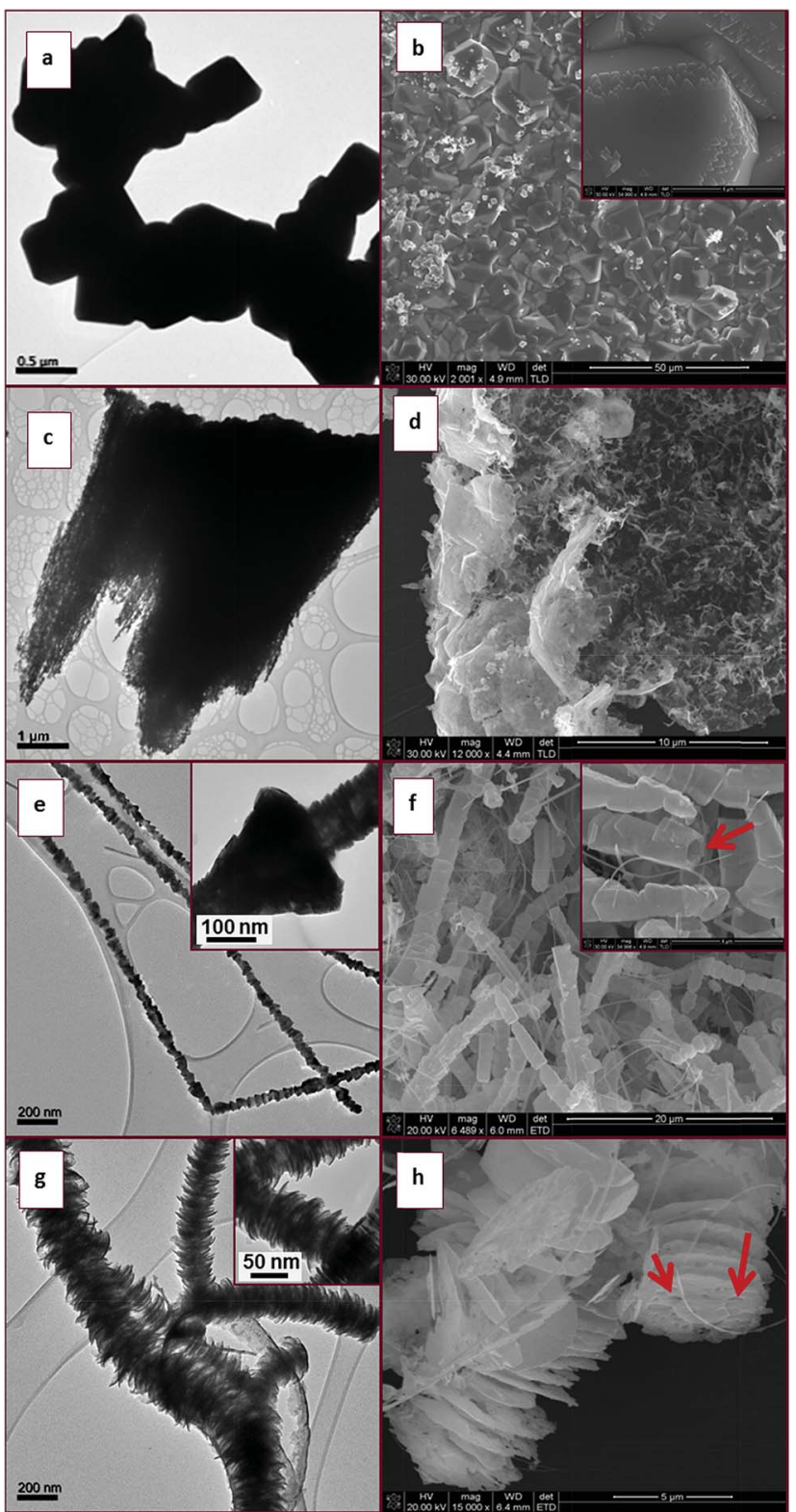

Fig. 2 (a) TEM and (b) SEM images of as purchased $\ln _{2} \mathrm{O}_{3}$ particles, (c) TEM and (d) SEM images of perforated materials formed at $700{ }^{\circ} \mathrm{C}$, (e) TEM and (f) SEM images of segmented rod like structures at $750^{\circ} \mathrm{C}$ (the arrow indicates the hollow core), (g) TEM and (h) SEM images of flaky structures at $800^{\circ} \mathrm{C}$ (the arrows show perforations). All reactions were performed by photolysis of $\mathrm{NH}_{3}$ only.

irregularly perforated material (Fig. $2 \mathrm{c}$ and d). At $750{ }^{\circ} \mathrm{C}$ TEM and SEM images revealed that rod-like structures had formed (Fig. 2e and f). These rod-like structures possessed rough surfaces (Fig. 2e). High magnification TEM analysis of the rodlike structures showed that the roughness is due to stacking of cone like pieces that form the overall structure (Fig. 2e insert). An arrow shows that some of the cones are actually hollow, an indication that the rod-like structures are tubular in nature (Fig. $2 \mathrm{f}$ insert).

At $800{ }^{\circ} \mathrm{C}$ SEM analysis revealed that unusual 1D structures were formed from stacked disc-like units (Fig. 2h). The flake- like nature of the stacked discs creates an illusion of a rod-like structure, as revealed by the high magnification TEM image (Fig. $2 \mathrm{~g}$ insert). The flakes had a rough surface texture and arrows indicate some of the perforations on the surface of the flakes (Fig. 2h). This disc type of morphology has not been reported previously in the literature for InN nanostructures.

In summary, even though a $100 \%$ pure InN material was not synthesized from photolysis of only $\mathrm{NH}_{3}$, information on the structure generation as a function of temperature was obtained. We suggest that the $\operatorname{In}_{2} \mathrm{O}_{3}$ was etched by the species generated by photolysis of $\mathrm{NH}_{3}$ in the process of nitridation (in the absence of photolysis no InN was made under the reaction conditions studied). No oxide nanowires were observed but the parent oxide particles were observed. The species formed from $\mathrm{NH}_{3}$ degrade the oxide leading to formation of $\mathrm{InN}$ with a disc like appearance and with increased temperature these discs become longer and more flake like.

\subsection{InN synthesis by photolysis of both indium oxide and $\mathrm{NH}_{3}$}

2.2.1 XRD studies. In an attempt to obtain pure $\mathrm{InN}, \operatorname{In}_{2} \mathrm{O}_{3}$ and $\mathrm{NH}_{3}$ were both irradiated with UV-light at different temperatures $\left(700-800{ }^{\circ} \mathrm{C}\right.$ ) for a maximum period of $2 \mathrm{~h}$ to minimise concurrent photodecomposition of the product (Table S1 $\dagger$ ). XRD patterns obtained from the as-synthesised material prepared at different temperatures showed enhanced improvement in InN purity with increasing temperature (Fig. 3). The (101) peak intensity of the cubic $\operatorname{In}_{2} \mathrm{O}_{3}$ reactant (seen at $35.8^{\circ} \theta$ ) decreased gradually with increasing temperature until it was hardly observable at $800{ }^{\circ} \mathrm{C}$; inversely the InN (002) peak intensity at $36.6^{\circ} \theta$ became prominent with temperature (Fig. 3). Thus, photoactivation of both $\operatorname{In}_{2} \mathrm{O}_{3}$ and $\mathrm{NH}_{3}$ improved the chemical purity of the InN product. Total conversion of $\operatorname{In}_{2} \mathrm{O}_{3}$ to InN was however not attained in $2 \mathrm{~h}$ in the temperature range studied.

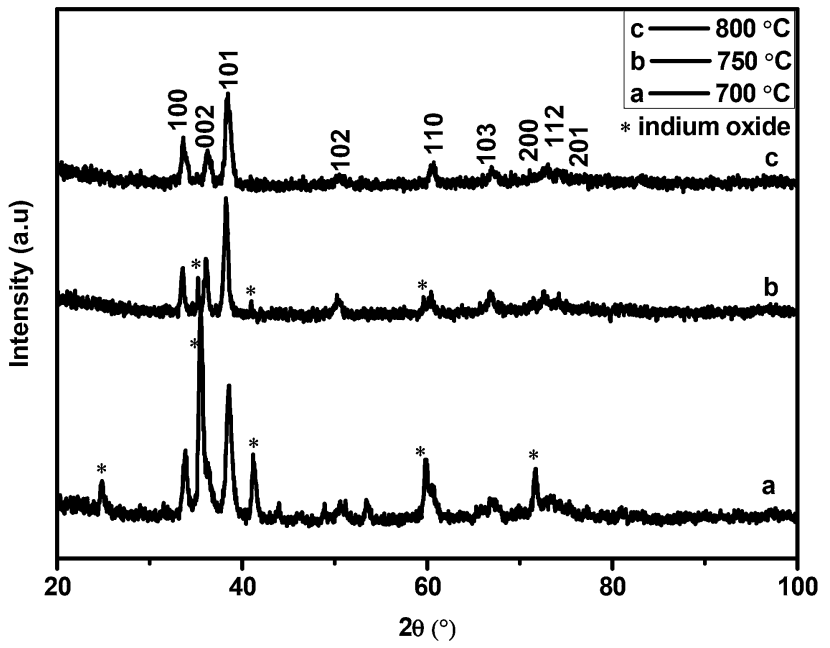

Fig. 3 XRD patterns of wurtzite $\mathrm{InN}$ materials prepared from photolysis of $\mathrm{In}_{2} \mathrm{O}_{3}$ and $\mathrm{NH}_{3}$ in $2 \mathrm{~h}$ at different temperatures. 
2.2.2 Microscopy studies. TEM and SEM analyses of the product formed at different temperatures were studied and the images revealed that there is a gradual change from $\operatorname{In}_{2} \mathrm{O}_{3} 3 \mathrm{D}$ microparticles to $3 \mathrm{D}$ InN microstructures at $700{ }^{\circ} \mathrm{C}$ (Fig. $4 \mathrm{a}$ and b); and finally to $1 \mathrm{D} \mathrm{InN} \mathrm{nanostructures} \mathrm{at} 800{ }^{\circ} \mathrm{C}$ (Fig. $4 \mathrm{e}$ and f). A change from microparticles to nanotubes with temperature had occurred. At $700{ }^{\circ} \mathrm{C}$ porous particles dominate (Fig. 4a and b). At $750{ }^{\circ} \mathrm{C}$ few particles and microsheets coexist with amorphous nanowires (Fig. 4c and d). It can be seen from the TEM image that some nanowires show $Y$-junction features (Fig. 4c insert). At $800{ }^{\circ} \mathrm{C}$ TEM and SEM analyses revealed InN nanotubes (diameter $\sim 40 \mathrm{~nm}$ ) as the dominant species (Fig. $4 \mathrm{e}$ and $\mathrm{f}$ ).

\subsection{Photolysis of indium oxide and $\mathrm{NH}_{3}$ as a function of time}

2.3.1 XRD studies. XRD analysis of the materials made in $2 \mathrm{~h}$ at $750{ }^{\circ} \mathrm{C}$ and $800{ }^{\circ} \mathrm{C}$ indicated the presence of minute residual oxide impurities as compared to materials made at $700{ }^{\circ} \mathrm{C}$ (Fig. 3). The impact of time on the $\mathrm{InN}$ materials was therefore investigated at $750{ }^{\circ} \mathrm{C}$ and $800{ }^{\circ} \mathrm{C}$. Reactions were performed at both temperatures in the time range of $30 \mathrm{~min}$ to

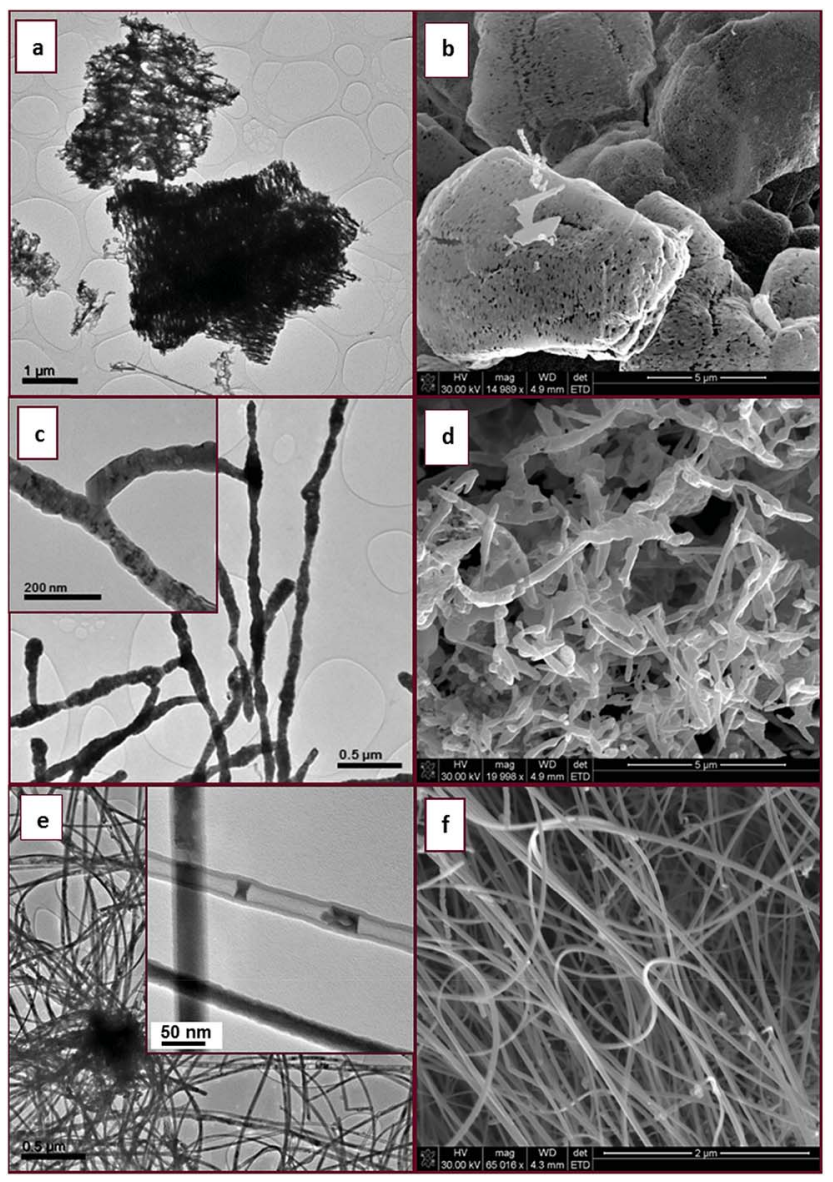

Fig. 4 (a) TEM and (b) SEM images of porous $\ln N$ particles showing irregular pores at $700{ }^{\circ} \mathrm{C}$, (c) TEM and (d) SEM images of amorphous nanowires at $750{ }^{\circ} \mathrm{C}$, (e) TEM and (f) SEM images of partially filled InN tubes at $800{ }^{\circ} \mathrm{C}$. All reactions were held for $2 \mathrm{~h}$ at their respective temperatures.

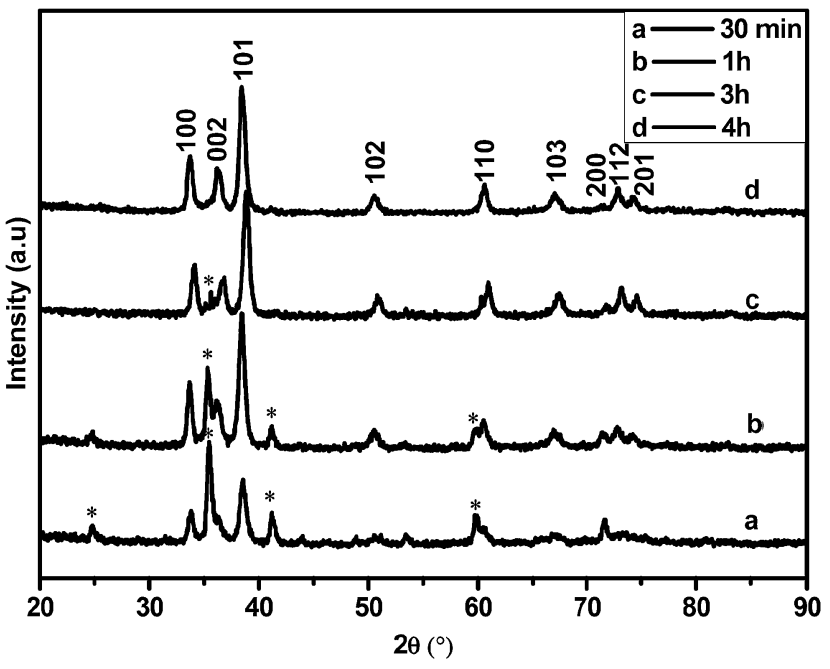

Fig. 5 XRD patterns of wurtzite $\operatorname{lnN}$ materials prepared at $750{ }^{\circ} \mathrm{C}$ for different duration.

4 h. Microscopy analysis of materials collected from times shorter than $2 \mathrm{~h}$ also provided information on the mechanism of conversion from $3 \mathrm{D} \operatorname{In}_{2} \mathrm{O}_{3}$ microstructures to $1 \mathrm{D}$ InN nanostructures. XRD analysis of materials made at 750 and $800{ }^{\circ} \mathrm{C}$, showed gradual improvement in chemical purity (Fig. 5 and 6). The XRD patterns collected from the product obtained after reaction times of 3-4 $\mathrm{h}$ indicated complete conversion of the oxide to indium nitride (Fig. 5 and 6). However, the production of pure InN using longer reaction times, under UV irradiation, also gave metallic indium droplets that were detected at the base of the quartz boat. This reduced the yield of the final InN product.

2.3.2 Microscopy analysis of $\operatorname{InN}$ nanowires at $750{ }^{\circ} \mathrm{C}$ as a function of time. Nanowires were observed for all reactions performed at $750{ }^{\circ} \mathrm{C}$. The nanowires varied in abundance, length and crystallinity with time. The TEM and SEM images showed that nitriding $\operatorname{In}_{2} \mathrm{O}_{3}$ at $750{ }^{\circ} \mathrm{C}$ for $30 \mathrm{~min}$ largely resulted

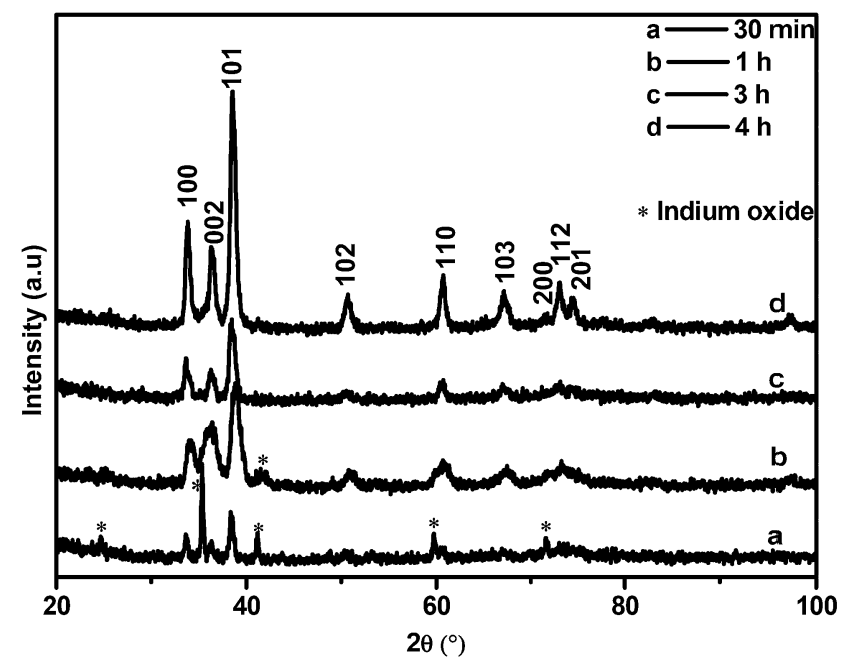

Fig. $6 \mathrm{XRD}$ patterns of the wurtzite $\ln \mathrm{N}$ product synthesised by photoactivation of $\ln _{2} \mathrm{O}_{3}$ and $\mathrm{NH}_{3}$ at $800{ }^{\circ} \mathrm{C}$ as a function of time. 


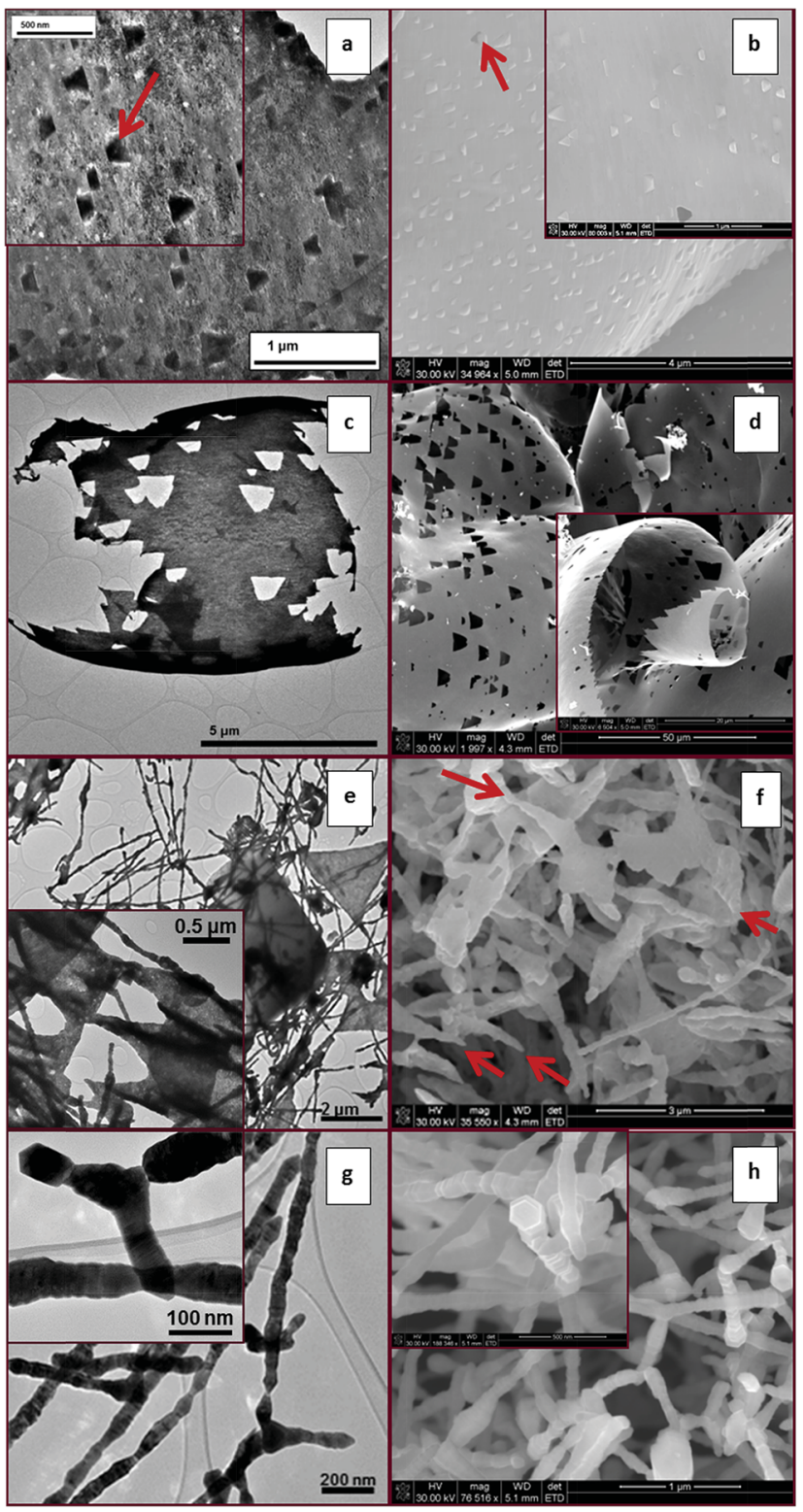

Fig. 7 (a) TEM and (b) SEM images of $2 \mathrm{D}$ microsheets at $750{ }^{\circ} \mathrm{C}$ for $30 \mathrm{~min}$; (c) TEM and (d) SEM images of perforated 2D microsheets at $750{ }^{\circ} \mathrm{C}$ for $1 \mathrm{~h}$; (e) TEM and (f) SEM images of amorphous InN nanowires formed from $2 \mathrm{D}$ microsheets at $750{ }^{\circ} \mathrm{C}$ for $2 \mathrm{~h}$; (g) TEM and (h) SEM images of $\operatorname{lnN}$ nanowires at $750^{\circ} \mathrm{C}$ for $3-4 \mathrm{~h}$.

in the formation of 2D microsheets. The TEM and SEM images of the 2D microsheets showed rhombohedral particles embedded into the matrix of the $2 \mathrm{D}$ microsheet and thus created mounds (Fig. 7a and b). A high magnification TEM image of the sheet showed that the edges around the rhombohedral particles were slightly perforated and created crevices (Fig. 7a insert). These crevices are points of weakness on the 2D sheet. The TEM and SEM images showed the rhombohedral particles on the 2D sheet indicated by arrows (Fig. 7a and b). Nitriding for $1 \mathrm{~h}$ at $750{ }^{\circ} \mathrm{C}$ resulted information of porous $2 \mathrm{D}$ microsheets with rhombohedral holes of varying sizes due to loss of the rhombohedral particles originally embedded in the 2D structure.
2.3.3 Microscopy analysis of InN nanotubes at $800{ }^{\circ} \mathrm{C}$ as a function of time. Interestingly, the structures obtained from nitriding 3D $\operatorname{In}_{2} \mathrm{O}_{3}$ particles at $800{ }^{\circ} \mathrm{C}$ deviate completely from those obtained at $750{ }^{\circ} \mathrm{C}$ indicating that the mechanism of formation is temperature dependent. The sample made in $30 \mathrm{~min}$ at $800{ }^{\circ} \mathrm{C}$ consisted largely of the $\operatorname{In}_{2} \mathrm{O}_{3}$ particles with only a few tubes (Fig. 8a and b) and this finding is consistent with XRD data. After $1 \mathrm{~h}$ the material contained a small fraction of remnants of $\operatorname{In}_{2} \mathrm{O}_{3}$ particles but InN nanotubes now dominated the mixture (Fig. 8c and d). An impressive improvement in selectivity of tubes over other structures is seen after $2-3 \mathrm{~h}$ (Fig. 8e and f). Finally complete conversion to InN nanotubes is noted after $4 \mathrm{~h}$ (Fig. $8 \mathrm{~g}$ and $\mathrm{h}$ ). High magnification TEM analysis

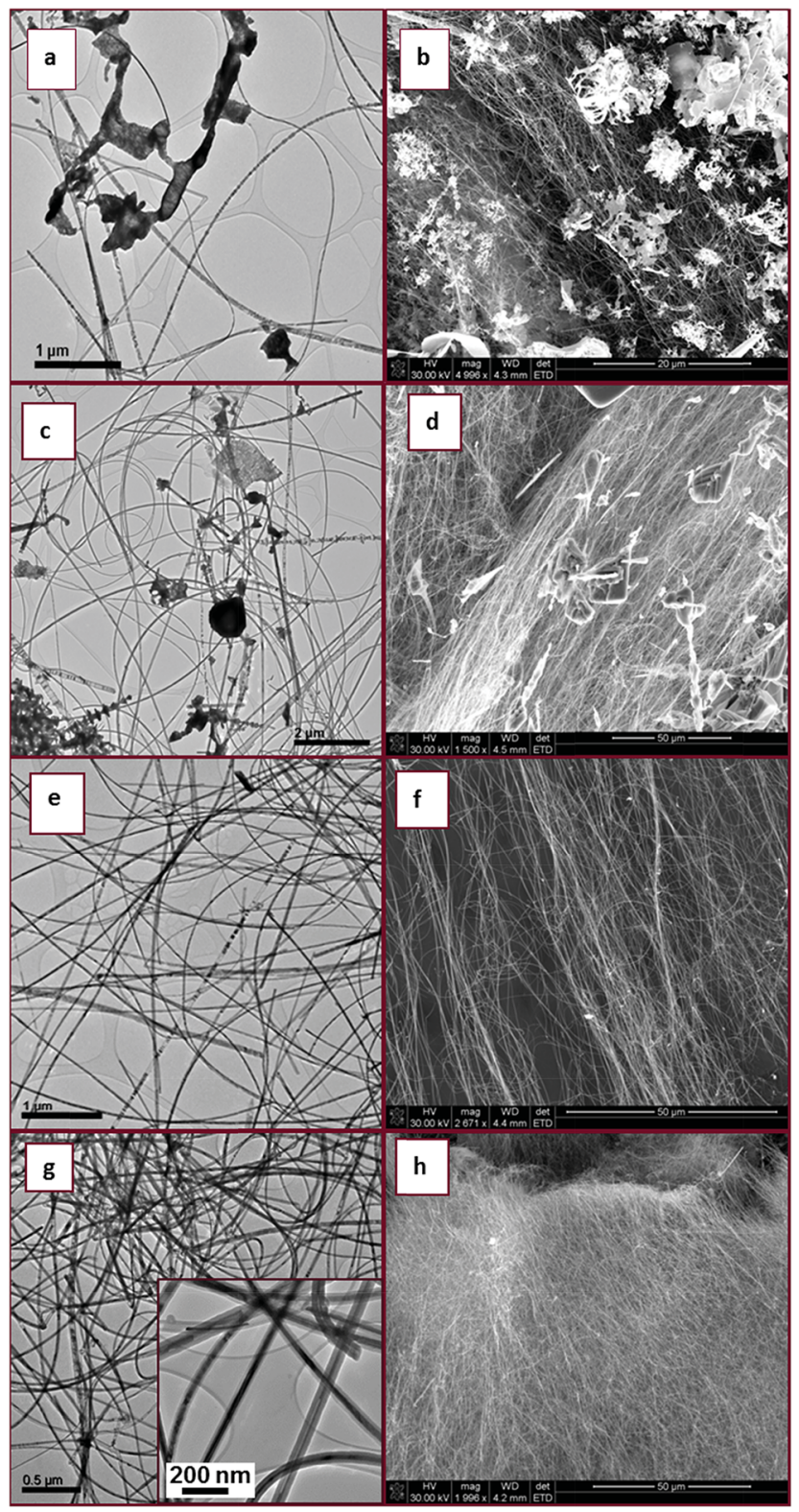

Fig. 8 (a) TEM and (b) SEM images of $\ln N$ nanotubes at $800{ }^{\circ} \mathrm{C}$ in $30 \mathrm{~min}$. (c) TEM and (d) SEM images of the nanotubes at $800^{\circ} \mathrm{C}$ for $1 \mathrm{~h}$ (e) TEM and (f) SEM images of the nanotubes at $800^{\circ} \mathrm{C}$ for $3 \mathrm{~h}$, (g) TEM and (h) SEM images of the nanotubes at $800^{\circ} \mathrm{C}$ for $4 \mathrm{~h}$. 
revealed that the nanotubes are partially filled with indium (Fig. $8 \mathrm{~g}$ insert). Approximately $90 \%$ of the InN nanotubes made in this study are partially filled with indium. The indium filled nanotubes have a core-shell structure appearance (Fig. 8g insert). TEM analysis revealed that approximately $60 \%$ of the InN nanotubes have diameters around 30-40 nm (Fig. 9), and are a few hundred microns in length (Fig. 8h).

To our knowledge indium filled InN nanotubes have not been previously reported. However, GaN nanotubes partially filled with indium have been achieved through indium assisted thermal evaporation. It was suggested that indium played an important role in the formation of nanotubes since spherical indium particles were found at the tips of the GaN tubes. ${ }^{31} \mathrm{We}$ propose that InN nanotubes may develop from both $2 \mathrm{D}$ sheets and $3 \mathrm{D}$ microparticles as long as the reaction conditions generate an indium catalyst essential for tube formation. In our study the general quality and selectivity of the product (InN) improved gradually with increasing time of reaction.

\subsection{Spectral properties of In filled InN nanotubes}

Fig. 10 shows the Raman spectrum of the partially filled InN nanotubes made at $800{ }^{\circ} \mathrm{C}(2 \mathrm{~h})$. The $\mathrm{E}_{2}$ high mode of the wurtzite InN is observed at $478 \mathrm{~cm}^{-1}$. The strain-free Raman frequency of the $\mathrm{E}_{2}$ high mode has been reported to be $490 \mathrm{~cm}^{-1}$ for wurtzite $\mathrm{InN}^{32}$ Hence it is blue shifted relative to the reported position for strain free InN. Usually a shift to lower wavenumbers indicates the presence of tensile stress. The Raman peak at $581 \mathrm{~cm}^{-1}$ is also blue shifted $\left(\sim 4 \mathrm{~cm}^{-1}\right)$ relative to the $\mathrm{A}_{1}$ longitudinal optical (LO) mode reported at 585-590 $\mathrm{cm}^{-1} \cdot{ }^{33}$ The data thus indicates tensile stress in the material.

The fundamental band gap value for InN is still a subject of controversy. The values from the reported data vary between $0.65 \mathrm{eV}$ to $2.1 \mathrm{eV}^{34}$ Various phenomena, mechanisms and processes such as deep level traps, the Mie resonance, the Burstein-Moss effect, quantum confinement, oxygen incorporation and nitrogen-vacancies have been proposed to explain the band gap values measured for InN. ${ }^{34}$ It has also been shown

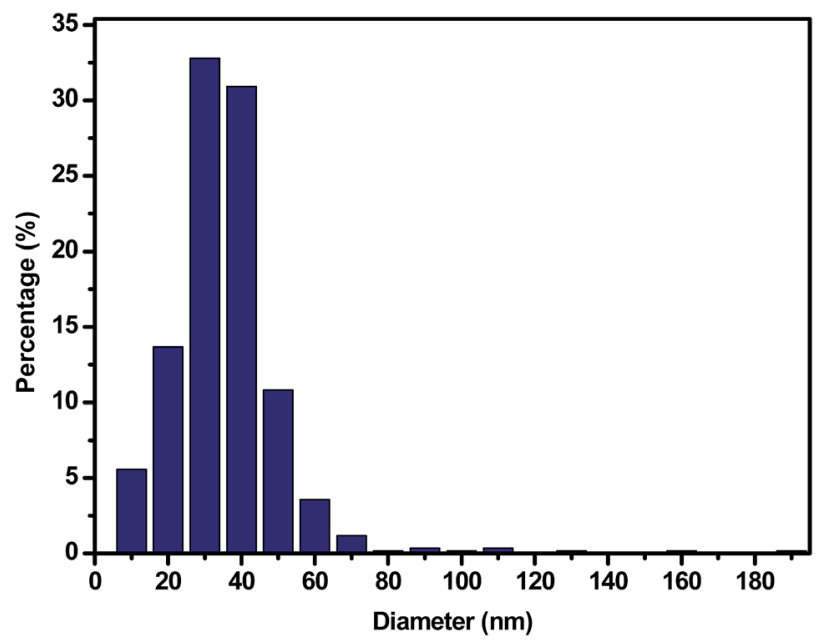

Fig. 9 InN nanotube diameters obtained from TEM studies.

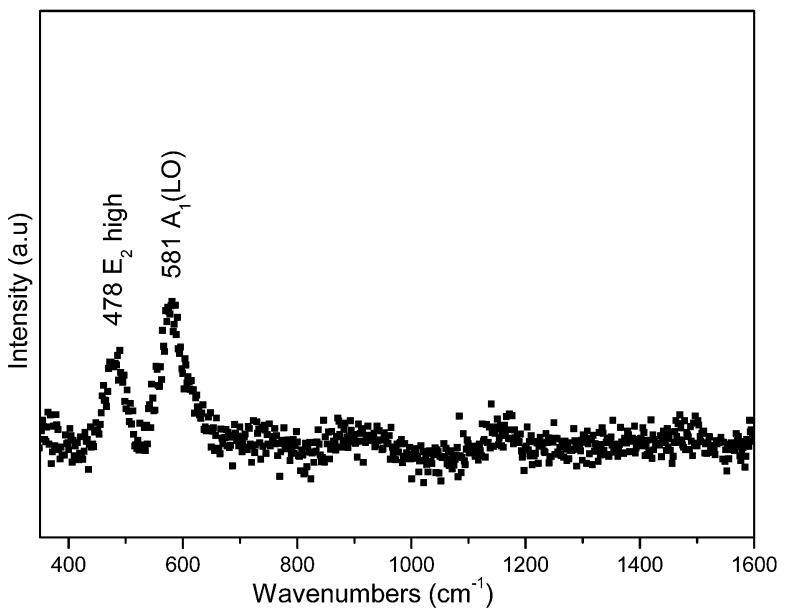

Fig. 10 Raman spectrum of partially filled $\mathrm{InN}$ nanotubes made at $800^{\circ} \mathrm{C}$

that deviations in the In:N stoichiometric ratio can result in a large change in the band gap. ${ }^{35}$ Polycrystallinity has been identified as one of the factors that may lead to high band gap values. In InN materials polycrystallinity has been associated with excess nitrogen; and it has been suggested that excess nitrogen incorporation occurs largely when non-equilibrium growth techniques such as RF sputtering, and MBE are used. ${ }^{36}$

UV-vis/NIR diffuse reflectance spectroscopy was used in this study to determine the band gap value of the partially filled InN nanotubes made at $800{ }^{\circ} \mathrm{C}$ for $4 \mathrm{~h}$. It has been suggested that the DRS technique can allow for the extraction of the band gap values of powder semiconductors without any ambiguity. ${ }^{37}$ The estimated band gap energy of partially filled tubes made at $800{ }^{\circ} \mathrm{C}$ was found to be $1.89 \mathrm{eV}$ (Fig. 11 insert). This value is close to the original band gap data reported for InN $(1.9 \mathrm{eV})^{38}$ but much larger than the more recent band gap values reported $(0.7 \mathrm{eV})$ for InN. ${ }^{39}$ The observed band gap values might be influenced by the possible presence of defects suggested by

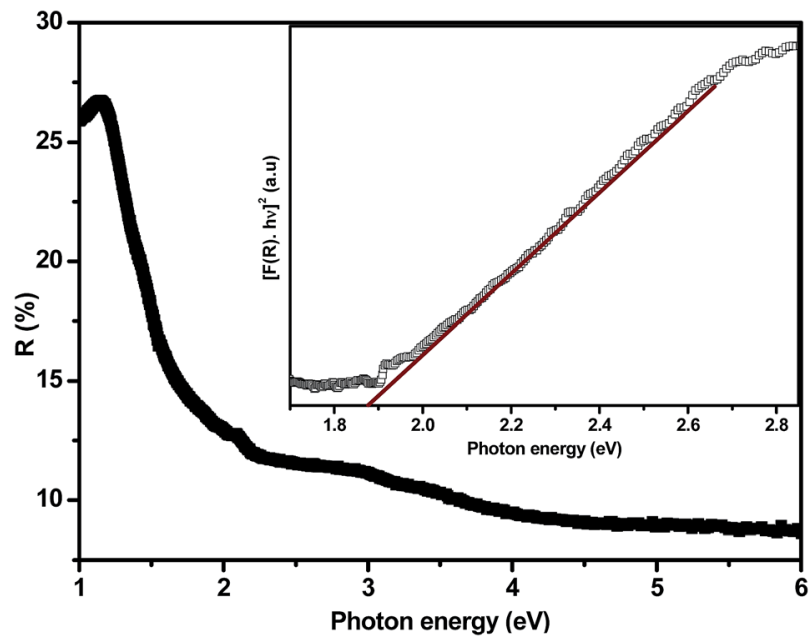

Fig. 11 Diffuse reflectance spectra of partially filled $\ln N$ nanotubes at $800{ }^{\circ} \mathrm{C}$. The insert shows the Kubelka-Munk function analyses of the DRS of partially filled $\ln N$ tubes at $800^{\circ} \mathrm{C}$. 
tensile stress indicated by Raman analysis. It also might to some extent be influenced by the indium within the core of the nanotubes. ${ }^{34}$ The indium could increase the overall carrier concentration of the InN nanotubes. Large carrier concentrations have been correlated to high band gap values associated with the Burstein-Moss effect. ${ }^{\mathbf{4 0}}$

\subsection{Reaction mechanism}

It is interesting to note that the morphologies of the synthesized 1D InN nanostructures depend remarkably on small changes in the growth temperature. Ding et al. reported that in the vapourliquid-solid (VLS) mechanism the shape of a 1D structure is determined by the interfacial lattice mismatch between a catalyst particle and a 1D structure. ${ }^{41}$ They however suggested that amongst other factors, temperature played a crucial role in determining the shape of a 1D structure but a detailed mechanism was not provided. Bando et al. and others suggested that in a vapour-solid (VS) mechanism, hollow InN nanotubes were formed by a diffusion-limited process at high temperatures, while the solid InN nanowires were formed by a kinetically limited process at lower temperatures in a VS mechanism. .4,42,43 $^{\mathbf{4}}$

The InN obtained from the reaction between $\operatorname{In}_{2} \mathrm{O}_{3}$ and $\mathrm{NH}_{3}$ generated by photo-activation of only $\mathrm{NH}_{3}$, showed a change in the morphology with time and temperature. All samples contained small amounts of $\operatorname{In}_{2} \mathrm{O}_{3}$. The photo-activated reaction of both $\mathrm{In}_{2} \mathrm{O}_{3}$ and $\mathrm{NH}_{3}$, as a function of temperature also gave rise to different morphologies of pure InN.

For all reactions in which only $\mathrm{NH}_{3}$ was photolysed, a minimum of $6 \mathrm{~h}$ appears necessary to obtain InN even though it was still impure. The morphologies varied with temperature indicating that the mechanism of formation is temperature dependent.

The TEM and SEM analyses shed some light into the progressive development of $1 \mathrm{D}$ morphologies of InN from 3D $\mathrm{In}_{2} \mathrm{O}_{3}$ particles. It is suspected that the porous particles form from the solid $\operatorname{In}_{2} \mathrm{O}_{3}$ particles by thermal decomposition in a manner similar to that proposed by $\mathrm{Yu}$ et al. ${ }^{\mathbf{4 4 - 4 6}}$ This entails adsorption, diffusion and subsequent reaction of $\mathrm{NH}_{3}$ species on and within the $\operatorname{In}_{2} \mathrm{O}_{3}$ particle core. A InN shell would be formed from surface based reactions on the outside the $\operatorname{In}_{2} \mathrm{O}_{3}$ core, later converting to a porous hollow particle (Fig. S2 $\dagger$ ). The general reaction between $\mathrm{In}_{2} \mathrm{O}_{3}$ and $\mathrm{NH}_{3}$ proposed by several authors can explain the generation of $\mathrm{H}_{2} \mathrm{O}$ as a by-product. ${ }^{12,17,18,47}$ As decomposition of the $\operatorname{In}_{2} \mathrm{O}_{3}$ core proceeds in the presence of $\mathrm{NH}_{3}$, the generated $\mathrm{H}_{2} \mathrm{O}$ vapour accumulates in the core until the pressure, when high enough, weakens the shell of the particle generating tiny pores that allow the trapped gas to escape. Alternatively the pores could be formed by conversion of $\operatorname{In}_{2} \mathrm{O}_{3}$ to InN by $\mathrm{NH}_{3}$; in the process the structure changes, as $\mathrm{N}$ replaces O. This is to be contrasted with the mechanism proposed by Ashok and co-workers to interpret the synthesis of porous InN microcages. Ashok et al. observed porous microcages in the InN synthesis using a lower temperature $\left(650{ }^{\circ} \mathrm{C}\right)$ and a shorter reaction time $(1 \mathrm{~h})$. They suggested that microcages form by selfassembly of a few web-like structures controlled by a diffusion limited process. ${ }^{48}$ In another study InN microtubes with holes were observed and it was suggested that the holes were formed as a result of a lack of $\mathrm{InN}$ vapour in the reaction feed. ${ }^{\mathbf{1 2}}$

The kinetics and the reaction mechanism for the photochemical decomposition of ammonia by ultraviolet light has not yet been settled, ${ }^{49-51}$ and even in the simplest case of thermal $\mathrm{NH}_{3}$ decomposition several matters are still in dispute. ${ }^{52-54}$ However, both thermal and photochemical decomposition studies of $\mathrm{NH}_{3}$ have identified $\mathrm{N}_{2} \mathrm{H}_{4}$ as the molecular intermediate formed before conversion to $\mathrm{H}_{2}$ and $\mathrm{N}_{2}$ (molar ratio $3: 1$ ). ${ }^{50,52} \mathrm{NH}_{3}$ and $\mathrm{N}_{2} \mathrm{H}_{4}$ are known for their etching properties. We therefore propose that the $2 \mathrm{D}$ microsheets observed in this study are formed from surface etching of the 3D $\mathrm{In}_{2} \mathrm{O}_{3}$ particle agglomerates by UV-light, $\mathrm{NH}_{3}$ and $\mathrm{N}_{2} \mathrm{H}_{4}$. Based on differences in the parent particle size as well as differences in exposure of the individual particles in the agglomerate, to the etching agents, some particles are selectively etched faster than others creating the $2 \mathrm{D}$ sheet with uneven points. As a result the particles least affected by etching remain stuck in the sheet creating mounds. Prolonged etching of the sheet creates weak points around the particles stuck in the parent sheet and the particles fall off the $2 \mathrm{D}$ sheet leaving behind rhombohedral holes on the $2 \mathrm{D}$ sheet. This is to be contrasted with the proposition made by Schwenzer et al. ${ }^{\mathbf{1 1}}$ They suggested that $2 \mathrm{D}$ microplates were formed by degradation of the InN microtube walls. They also observed triangular shaped holes on the microtubes. Our study helps bring into focus the mechanism of formation for the triangular/rhombohedral shaped holes observed on the InN microtubes/sheets.

Further degradation of the porous 2D sheet results in selective growth of the InN nanowires from the corners of the pieces of the parent sheet in a manner similar to that described by Schwenzer et al. ${ }^{\mathbf{1 1}}$ They observed that the corners of the triangles of $2 \mathrm{D}$ InN plates grow into nanowires. They suggested that the co-existence of nano and microstructures indicated that the structures do not form independently from $\operatorname{In}_{2} \mathrm{O}_{3}$ but rather go through different stages. ${ }^{11}$ It is to be noted that another research study argued that the local differences in the morphology of InN structures suggested the independent growth of InN nano and microstructures. ${ }^{12}$ The schematic presentation of our proposed mechanism for $1 \mathrm{D}$ InN growth is presented in Fig. 12. The mechanism of nanowire growth from $2 \mathrm{D}$ sheets is to be contrasted with the mechanism of nanowire growth from microcages proposed by Ashok et al. ${ }^{48}$

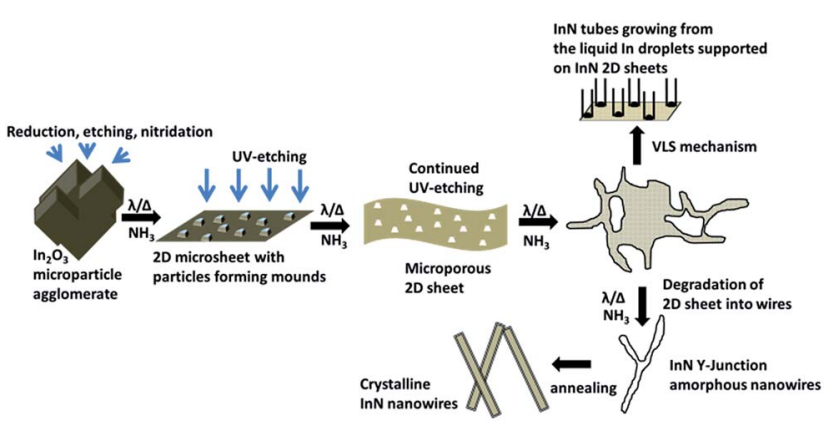

Fig. 12 Reaction mechanism showing etching effects due to both the UV and ammonia species. 
We believe that at high temperatures $\left(\geq 750{ }^{\circ} \mathrm{C}\right)$ decomposition of $\mathrm{NH}_{3}$ produces reducing species (e.g. $\left.\mathrm{N}_{2} \mathrm{H}_{4}, \mathrm{H}_{2}\right)$ in high abundance relative to reactions at low temperature. The reduction of $\operatorname{In}_{2} \mathrm{O}_{3}$ into indium is then highly favoured. The resulting indium metal particles embedded or supported on the $3 \mathrm{D}$ particle or the $2 \mathrm{D}$ sheet, could serve as catalysts from which indium filled InN nanotubes grow. This is supported by experiments we performed by conventional thermal nitridation of $\operatorname{In}_{2} \mathrm{O}_{3}$ (not shown), where at high temperatures all the $\operatorname{In}_{2} \mathrm{O}_{3}$ is converted to metallic indium. Thus UV irradiation aids in activating the nitriding species at lower temperatures to limit complete conversion to indium metal.

\section{Experimental}

$\mathrm{In}_{2} \mathrm{O}_{3}$ powder (Aldrich, particle size $300-600 \mathrm{~nm}, 99.99 \%$ purity) was placed in a quartz boat $(L: 25 \mathrm{~mm}, D: 8 \mathrm{~mm}$ ) that had been cleaned in ethanol. The boat was then loaded into a long quartz tube ( $L: 800 \mathrm{~mm}, D: 20 \mathrm{~mm}$ ) which was installed horizontally into a furnace. The furnace has an opening $(D: 30 \mathrm{~mm})$ that allowed light from a mercury UV lamp in to the mid-region of the furnace to illuminate the tube and its contents. A $400 \mathrm{Watt}$ medium pressure mercury UV lamp (model no. 3040, Photochemical reactors Ltd) was situated in a housing equipped with a cooling system (Fig. 1).

The quartz tube was degassed and purged with high-purity (99.999\%) nitrogen. During the growth process, $400 \mathrm{sccm}$ of $\mathrm{NH}_{3}$ (anhydrous, 99.999\%) was introduced into the tube. The flow rate of $\mathrm{NH}_{3}$ was programmed and maintained at $400 \mathrm{sccm}$ using a Brookes mass flow controller at atmospheric pressure. The exhaust $\mathrm{NH}_{3}$ was bubbled through an oil bubbler before being discharged into the atmosphere. The furnace was set to $700-800{ }^{\circ} \mathrm{C}$ (the temperature error, $\pm 2{ }^{\circ} \mathrm{C}$ ) and was held there for 1-6 h, then cooled to room temperature under $\mathrm{NH}_{3}$.

Two sets of synthesis experiments were carried out. In the first setup (position 1), $\operatorname{In}_{2} \mathrm{O}_{3}$ powder was not irradiated by the UV lamp to prevent secondary photolysis of the product (Fig. 1) while varying temperature. In the second setup (position 2), both reactants $\left(\mathrm{In}_{2} \mathrm{O}_{3}\right.$ and $\left.\mathrm{NH}_{3}\right)$ were irradiated while varying the synthesis temperature and time (1-4 h). The breakdown of all the reactions and the reaction parameters varied is tabulated in Table S1 (ESI $\dagger$ ). A fluffy wool-like grey product was generated at the surface of the quartz boat after nitriding the reactant. In a typical optimised experiment $0.2 \mathrm{~g}$ of $\operatorname{In}_{2} \mathrm{O}_{3}$ was used and $0.08 \mathrm{~g}$ of partially filled InN nanotubes was obtained. XRD data used for structural analysis was collected on a Bruker D2 diffractometer with $\mathrm{CuK} \alpha$ radiation. Morphologies were evaluated by SEM (NOVA) and TEM (Tecnai T12). The optical properties of InN nanotubes were characterized by diffuse reflectance spectroscopy (Praying Mantis DRS Cary 500) and Raman spectroscopy (Jobin Yvon LabRAM).

\section{Conclusions}

In this study we have indicated the use of a combined thermal/ UV photolysed approach to make InN materials with a wide range of shapes. Photolysis of the $\mathrm{NH}_{3}$ provides a method to activate the $\mathrm{NH}_{3}$ that in the presence of $\operatorname{In}_{2} \mathrm{O}_{3}$ replaces the $\mathrm{O}$ atoms by $\mathrm{N}$ atoms (a reduction reaction). In doing so the $\operatorname{In}_{2} \mathrm{O}_{3}$ structure converts from a 3D structure to a $1 \mathrm{D}$ tubular material. Secondary growth processes lead to the final structures observed. The InN material that makes the tubes does so by means of supersaturation and nucleation from the catalytic liquid indium metal phase via a VLS mechanism. The anisotropic alignment of the indium filled InN nanotubes seen in all SEM images is a typical feature of the VLS method. The rod-like structures made of cones as well as flaky rods could be formed by a VS mechanism.

Photolysis of the $\mathrm{In}_{2} \mathrm{O}_{3}$ (as well as the $\mathrm{NH}_{3}$ ) results in the formation of completely different structures. In this case the replacement of the $\mathrm{O}$ in the $\operatorname{In}_{2} \mathrm{O}_{3}$ by $\mathrm{N}$ is aided by the photolysis process. Thus, the solid particles become porous on photolysis as the replacement reaction of $\mathrm{O}$ by $\mathrm{N}$ progresses $\left(700^{\circ} \mathrm{C}\right)$. With an increase in temperature $\left(800{ }^{\circ} \mathrm{C}\right)$, a pure $\mathrm{InN}$ is formed as more indium filled InN tubes are formed. However, overreduction occurs and indium metal now readily forms.

This study indicates the rich range of InN materials that is accessible by simple synthetic strategies. The study also indicates that the various structures are all linked together i.e. the structures form from each other. More work will be required to gain further insight into these shape/size transformation reactions. Whether the methodology can be extended to the synthesis of other metal nitride materials will need further experimentation.

\section{Acknowledgements}

The authors would like to thank the DST-NRF CoE in Strong Materials, the DST-IBSA Nanotechnology Project (80287) and the DST-NRF SA-India research initiative program (76517) for funding.

\section{References}

1 J. B. MacChesney, Mater. Res. Bull., 1970, 5, 783.

2 S. Vaddiraju, A. Mohite, A. Chin, M. Meyyappan, G. Sumanasekera, B. W. Alphenaar and M. K. Sunkara, Nano Lett., 2005, 5, 1625.

3 T. J. Kistenmacher and W. A. Bryden, Appl. Phys. Lett., 1991, 59, 1844.

4 Y. Xia, P. Yang, Y. Sun, Y. Wu, B. Mayers, B. Gates, Y. Yin, F. Kim and H. Yan, Adv. Mater., 2003, 15, 353.

5 C. N. R. Rao, F. L. Deepak, G. Gundiah and A. Govindaraj, Prog. Solid State Chem., 2003, 31, 5.

6 M.-S. Hu, W.-M. Wang, T. T. Chen, L.-S. Hong, C.-W. Chen, C.-C. Chen, Y.-F. Chen, K.-H. Chen and L.-C. Chen, Adv. Funct. Mater., 2006, 16, 537.

7 H. Xu, Z. Liu, X. Zhang and S. Hark, Appl. Phys. Lett., 2007, 90, 113105.

8 J. Zhang, L. Zhang, X. Peng and X. Wang, J. Mater. Chem., 2002, 12, 802.

9 T. Tang, S. Han, W. Jin, X. Liu, C. Li, D. Zhang, C. Zhou, B. Chen, J. Han and M. Meyyapan, J. Mater. Res., 2004, 19, 424. 
10 S. Luo, W. Zhou, W. Wang, Z. Zhang, L. Liu, X. Dou, J. Wang, X. Zhao, D. Liu and Y. Gao, Appl. Phys. Lett., 2005, 87, 063109.

11 B. Schwenzer, L. Loeffler, R. Seshadri, S. Keller, F. F. Lange, S. P. DenBaars and U. K. Mishra, J. Mater. Chem., 2004, 14, 637.

12 W. Jung, C. S. Ra and B. Min, Bull. Korean Chem. Soc., 2005, 26, 1354.

13 X. M. Cai, F. Ye, S. Y. Jing, D. P. Zhang, P. Fan and E. Q. Xie, Appl. Surf. Sci., 2008, 255, 2153.

14 L. W. Yin, Y. Bando, D. Golberg and M. S. Li, Adv. Mater., 2004, 16, 1833.

15 S. Z. Karazhanov, P. Ravindran, P. Vajeeston, A. Ulyashin, T. Finstad and H. Fjellvåg, Phys. Rev. B: Condens. Matter Mater. Phys., 2007, 76, 075129.

16 R. Weiher and R. Ley, J. Appl. Phys., 1966, 37, 299.

17 L. Gao, Q. Zhang and J. Li, J. Mater. Chem., 2003, 13, 154.

18 S. Luo, W. Zhou, Z. Zhang, L. Liu, X. Dou, J. Wang, X. Zhao, D. Liu, Y. Gao and L. Song, Small, 2005, 1, 1004.

19 S. Luo, W. Zhou, Z. Zhang, X. Dou, L. Liu, X. Zhao, D. Liu, L. Song, Y. Xiang and J. Zhou, Chem. Phys. Lett., 2005, 411, 361.

20 Y. Hirota and O. Mikami, Electron. Lett., 1985, 21, 77.

21 D. Ehrlich, R. Osgood Jr and T. Deutsch, J. Vac. Sci. Technol., 1982, 21, 23.

22 V. Donnelly, M. Geva, J. Long and R. Karlicek, Appl. Phys. Lett., 1984, 44, 951.

23 H. Ando, H. Inuzuka, M. Konagai and K. Takahashi, J. Appl. Phys., 1985, 58, 802.

24 G. J. Kavarnos and N. J. Turro, Chem. Rev., 1986, 86, 401.

25 B. Gellert and U. Kogelschatz, Appl. Phys. B, 1991, 52, 14.

26 D. Ehrlich and R. Osgood Jr, Thin Solid Films, 1982, 90, 287.

27 D. Yu, X. Sun, C. Lee, I. Bello, S. Lee, H. Gu, K. Leung, G. Zhou, Z. Dong and Z. Zhang, Appl. Phys. Lett., 1998, 72, 1966.

28 W. Shi, Y. Zheng, N. Wang, C. Lee and S. Lee, Chem. Phys. Lett., 2001, 345, 377.

29 X. Duan and C. M. Lieber, J. Am. Chem. Soc., 2000, 122, 188. 30 Y.-K. Chang and F. C.-N. Hong, Mater. Lett., 2009, 63, 1855.

31 L.-W. Yin, Y. Bando, Y.-C. Zhu, D. Golberg and M.-S. Li, Appl. Phys. Lett., 2004, 84, 3912.

32 X. Wang, S.-B. Che, Y. Ishitani and A. Yoshikawa, Appl. Phys. Lett., 2006, 89, 171907.

33 V. Y. Davydov and A. Klochikhin, Semiconductors, 2004, 38, 861.
34 K. Butcher and T. Tansley, Superlattices Microstruct., 2005, $38,1$.

35 A. E. Morales, E. S. Mora and U. Pal, Rev. Mex. Fis. S, 2007, 53, 18.

36 K. Scott, A. Butcher, M. Wintrebert-Fouquet, P. P. T. Chen, K. E. Prince, H. Timmers, S. K. Shrestha, T. V. Shubina, S. V. Ivanov and R. Wuhrer, Phys. Status Solidi C, 2005, 2, 2263.

37 H. Timmers, S. K. Shrestha and A. P. Byrne, J. Cryst. Growth, 2004, 269, 50.

38 M. Yoshimoto, H. Yamamoto, W. Huang, H. Harima, J. Saraie, A. Chayahara and Y. Horino, Appl. Phys. Lett., 2003, 83, 3480.

39 T. Matsuoka, H. Okamoto, M. Nakao, H. Harima and E. Kurimoto, Appl. Phys. Lett., 2002, 81, 1246.

40 W. Walukiewicz, S. Li, J. Wu, K. Yu, J. Ager Iii, E. Haller, H. Lu and W. J. Schaff, J. Cryst. Growth, 2004, 269, 119.

41 Y. Ding, P. X. Gao and Z. L. Wang, J. Am. Chem. Soc., 2004, 126, 2066.

42 E. P. Bakkers and M. A. Verheijen, J. Am. Chem. Soc., 2003, 125, 3440.

43 L. W. Yin, Y. Bando, J. H. Zhan, M. S. Li and D. Golberg, Adv. Mater., 2005, 17, 1972.

44 H.-D. Yu, M. D. Regulacio, E. Ye and M.-Y. Han, Chem. Soc. Rev., 2013, 42, 6006.

45 H.-D. Yu, Z.-Y. Zhang, K. Y. Win, J. Chan, S. H. Teoh and M.-Y. Han, Chem. Commun., 2010, 46, 6578.

46 H. Yu, D. Wang and M.-Y. Han, J. Am. Chem. Soc., 2007, 129, 2333.

47 Z. Chen, Y. Li, J. Jiang, C. Cao, T. Xu, Q. Chen, X. Xu and H. Zhu, RSC Adv., 2012, 2, 6806.

48 V. D. Ashok, T. Ghoshal and S. De, J. Phys. Chem. C, 2009, 113, 10967.

49 J. A. Kaye and D. F. Strobel, Icarus, 1983, 54, 417.

50 E. O. Wiig and G. B. Kistiakowsky, J. Am. Chem. Soc., 1932, 54, 1806.

51 N. Dietz, M. Straßburg and V. Woods, J. Vac. Sci. Technol., A, 2005, 23, 1221.

52 D. Dirtu, L. Odochian, A. Pui and I. Humelnicu, Cent. Eur. J. Chem., 2006, 4, 666.

53 J. C. Elgin and H. S. Taylor, J. Am. Chem. Soc., 1929, 51, 2059.

54 R. R. Wenner and A. O. Beckman, J. Am. Chem. Soc., 1932, 54, 2787. 